\title{
Maturation of Cerebral Connections and Fetal Behavior
}

\author{
Ivica Kostovic, Milos J udas \\ Section for Developmental Neuroscience, Department of Neuroscience, Croatian Institute for Brain Research \\ School of Medicine, University of Zagreb, Croatia \\ Correspondence: Ivica Kostovic, Professor of Neuroscience and Anatomy \\ Director, Croatian Institute for Brain Research, School of Medicine, University of Zagreb, Salata 12, 10000 Zagreb, Croatia \\ Phone: +385 14596 902, Fax: +385 14596 942, e-mail: ikostov@ hiim.hr
}

\begin{abstract}
M odern imaging methods enabled systematic studies of fetal behaviour as well as a continuation of that behaviour in prematurely born infants (for a review, see 1-4). Thefollowing question represents a great challenge for human developmental neurobiologist: what is the neurobiological basis of various behavioural patterns observed in human fetuses and preterm infants? ${ }^{2}$ First of all, it is essential to determine whether there is an early spontaneous (nonsensory-driven) activity and to what extent the cerebrum and the cerebral cortex may be involved. In addition, it is necessary to describe for each successive phase, the developmental status of neuronal circuitry and synaptic organization.

In this review, we present evidence on the development of cortical connections during different phases of fetal development and evaluate a possible functional significance of cerebral involvement.
\end{abstract}

\section{ENDOGENOUS AND SENSORY-DRIVEN ACTIVITY}

\section{Early Fetal Period: Early Endogenous Network and Spontaneous Activity}

Experimental evidence in several mammalian species has revealed that early neural network has endogeneous features and is characterized by spontaneous activity. ${ }^{5-8}$ In humans, that endogeneous cortical network is al ready present at 8 weeks post conception (WPC), i.e. at the end of embryonic period and the beginning of the fetal life. It contains very few synapses ${ }^{9}$ and it is very likely that some early born neurons ${ }^{10}$ communicate through nonsynaptic intercellular junctions. ${ }^{7,11}$ The early netw ork displays a characteristic oscillatory activity. ${ }^{12,8}$ It seems likely that this early spontaneous cortical activity has no correlates at the level of fetal motor behavior. However, endogeneous networks may elicit some motor activity in other parts of the brain and spinal cord. ${ }^{13}$ In particular, coordinated endogenously active oscillations of non-synaptic and synaptic junctions in the spinal cord may be actively patterned. ${ }^{13,7}$ The concept of early spontaneous activity is very important for the developmental neuroscience (for a review, see 7) and fetal neurology, for several reasons. First, it contradicts the old dogma which stated that the early activity was predominantly reflexogenic. Second, that spontaneous activity generates patterns needed for a refinement of developing neural connections. Indeed, this activity may shape the synaptogenesis. ${ }^{7}$ Third, the spontaneous activity contains spatiotemporal information required for activity-dependent competition. ${ }^{7}$ It should be emphasized that spontaneous activity may appear in a given brain «center» significantly before the onset of specific function of that part of the brain.

\section{Midfetal Period: Transient Neural Circuitry and Transient Behavioral Patterns}

Transient neural networks are determined by transient distribution of synapses, transient position of axons and the existence of transient postsynaptic neurons. These netw orks are interconected and form transient circuitry. Transient neural circuitry is spatially largely confined to transient fetal cellular zones. The largest and the most prominent of these transient fetal architectonic zones is the fibrillar and synapse-rich subplate zone, which also contains waiting axons and the majority of differentiated postmigratory neurons. ${ }^{14}$ From the clinical viewpoint, it is important to emphasize that subplate zone can be visualized by M R imaging ${ }^{15}$ invitro and in utero/invivo. ${ }^{16-18}$ In the midfetal period, transient fetal zones contain specific parts of endogeneous neuronal networks and represent the site of spontaneous activity. For example, this activity may manifest itself as some kind of (presently unspecified) complex fetal movements, ${ }^{1}$ which would eventually became modified by cerebral activity. The transient connectivity between transient cerebral zones and thalamus may serve this functional purpose as somatosensory trigger. One should bear in mind that, during the midfetal period, the neuronal migration is at its peak. A myriad of neurons generated in proliferative (ventricular and subventricular) zones migrate through the subplate zone toward the cortical plate. These migrating neurons may also be 
electrically active and thus contribute to transient patterns of activity. Further studies are needed to ascertain whether transient patterns of cerebral organization represent a structural basis for transient patterns of motor behaviour during the midfetal period.

\section{Late Fetal and Early Preterm Period: The Coexistence of Transient and Permanent Circuitry}

After 22-24 W PC, due to the development of afferent input from thalamus to cortical sensory areas, ${ }^{19-21}$ a new period of cortical functional organization begins. On the basis of experimental evidence $e^{22,7}$ and our data on the simultaneous presence of thalamocortical axons in the subplate zone and in the cortical plate, we proposed that during the late fetal and early preterm period the coexistence of transient and permanent circuitry (Fig. 1) represents a salient feature of the developing human cerebrum. ${ }^{23}$ This period has a central role in development and shaping of afferent thalamocortical pathways because at that developmental ages thalamocortical afferents maintain a strong input to neurons of the subplate zone but concurrently begin to relocate to their final target destination, i.e. the cortical plate. ${ }^{6}$ That type of structural organization very likely contributes to the appearance of characteristic and developmentally specific cortical waves. ${ }^{24-26}$ We believe that massive and heterogeneous afferent input to transient deep tiers of the developing cortex together with rapid laminar shifts in the distribution of afferent fibres represents the structural basis of the discontinuous nature of the early cortical activity in preterm infants. ${ }^{24}$ In this period both axons and neurons of the subplate zone may display a selective vulnerability, and that vulnerability in turn may exert a strong effect be on cognitive neurodevelopmental outcome after perinatal lesions. ${ }^{27,28}$ The most frequent «abnormal» finding in preterm infants, observed in more than $50 \%$ of cases, is so-called DEHSI. ${ }^{29} \mathrm{~W}$ ith respect to its spatial distribution within the fetal cerebral wall, that type of M R I signal abnormal ity al most certainly involves a portion of the subplate zone. ${ }^{29,28}$ Thus, it is reasonable to assume that lesions of this transitional zone may exert similar efects as lesions of the entire subplate zone. ${ }^{28}$

\section{Late Preterm and Newborn Period: Sensory-driven Activity}

A t present, very little is known about sensory-driven activity and possible effects of precocious stimulation of the cerebral cortex in late preterm infants and full-term newborns. It was demonstrated experimental ly that precocious visual stimulation in prematurely born rhesus monkeys did not change the rate of accretion of synapses in the visual cortex. ${ }^{30} \mathrm{H}$ owever, the same authors observed changes in the length of synaptic profiles. These findings strongly suggest that neurogenetic events which normally enfold before birth in preterm primates are predominantly enfolding according to intrinsic (genetic) programs, but upon sensory stimulation display a certain level of structural plasticity. That plasticity becomes more prominent with increasing age and in the neonatal period sensory-driven activity may assume a decisive role. For example, that was experimentally demonstrated for the formation of ocular dominance columns, suggesting that initial functional architecture of the cerebral cortex was established very early but undergoes plastic changes during subsequent critical period, which relay on distinct developmental mechanisms. ${ }^{31-33}$

\section{THE INVOLVEMENT OF CORTICAL CONNECTIONS IN FETAL AND PRETERM BEHAVIOR}

A s al ready stated, in the human cerebral cortex the first synapses develop around ${ }^{8}$ WPC. ${ }^{9}$ These synapses display structural features of functionally active synapses. However, they are present in very small number. During that early period, neither neurons involved in motor behavior or cortical cells which receive major somatosensory input from thalamus are not yet generated. ${ }^{34}$ Thus, at that early fetal period motor and somatosensory axes are not yet established. Cortical connections consist of monoaminergic afferents from the brain stem, ${ }^{35,36}$ cholinergic afferents from the basal forebrai ${ }^{37}$ and postsynaptic neurons of the so-called presubplate layer ${ }^{14}$ Postsynaptic candidate cells in the cortical plate are immature ${ }^{38,39}$ and synapses are formed only on their apical dendrites. ${ }^{9} \mathrm{~A} / \mathrm{l}$ that evidence clearly suggests that cerebral cortex and associated subcortical structures, such as striatum and thalamus, are quite immature and not yet involved in the earliest patterns of fetal behavior.

However, a new connectivity framework for possible functional involvement of the cerebral cortex develops during the midfetal period (15-20 WPC) due to concurrent increase in number of synapses $s^{9,14}$ and thalamocortical afferents ${ }^{14,40-42}$ in the subplate zone ${ }^{19,21,23}$ as well as the parallel development of efferent cortical pathways. ${ }^{43}$

During the midfetal period, thal amocortical afferents which convey somatosensory information are still waiting within the subplate zone and did not reach their synaptic targets in the cortical plate. ${ }^{14} \mathrm{As}$ this massive contingent of thal amocortical afferents still displays a crude and diffuse topographical distribution, it may be responsible for some noncoordinated movement patterns. The motor axis develops at a similar pace and cortical efferent projections are still on their way toward targets in striatum ${ }^{44}$ and the spinal cord. ${ }^{43}$ Such immaturity of thalamocortical and corticomotoneuronal connections suggests that cerebral cortex has no prominent role in generation of behavioral patterns during the midfetal period. It is only after 22-24. WPC that neural circuitry begins to connect cerebral cortex with somatic periphery. ${ }^{19,23} \mathrm{~T}$ wo sets of data present the evidence for the first real functional involvement of the cerebral 


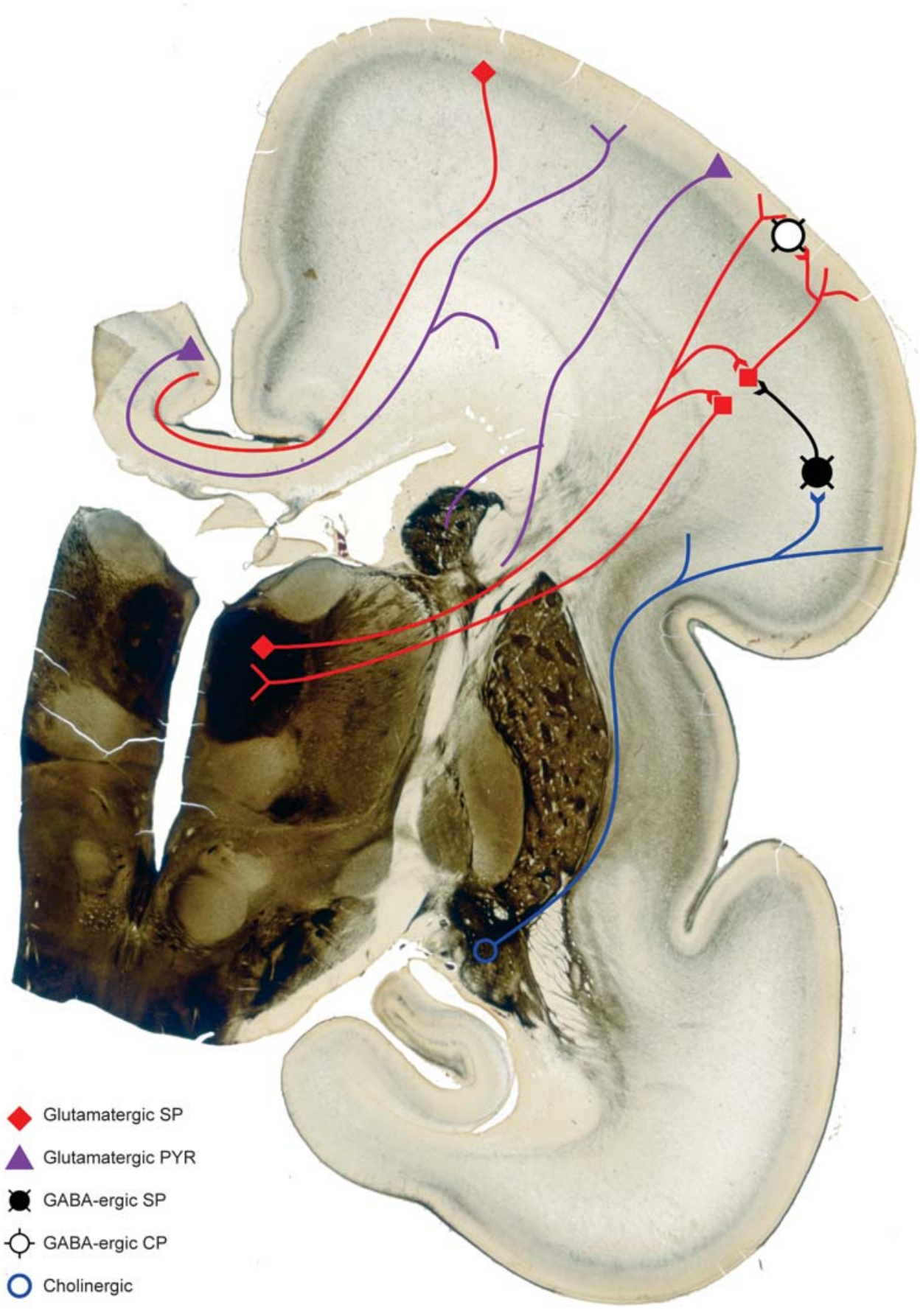

Fig. 1: The organization of neural connections in the cerebrum of early preterm infant. The circuitry shema is superimposed on the coronal histological section through the right cerebral hemisphere stained with acetylcholinesterase (AChE) technique.

Glutamatergic neurons (red diamonds) in the thalamus project simultaneously to subplate neurons and interneurons of the cortical plate, and receive reciprocal projections from glutamatergic neurons of the subplate zone. The subplate zone contains both glutamatergic (red diamonds) and GABAergic (red circle) neurons. Glutamatergic subplate neurons project to the cortical plate and establish the first synapses with cortical GABAergic interneurons (white circle). Transient neuronal circuits of the subplate zone receive cholinergic axons from the basal forebrain which establish synapses with GABAergic subplate neurons. Glutamatergic pyramidal neurons of the cortical plate (violet triangles) project and terminate in the striatum; however, callosal projection axons of another subset of glutamatergic pyramidal neurons did not enter the contralateral cortical plate and are situated in the deep periventricular position. 
cortex. First, after 24-26. W PC one can elicit evoked potentials in preterm infants. ${ }^{45-47}$ Second, it was recently demonstrated that cortical responses can be elicited by peripheral pain stimulus in early preterm infants. ${ }^{20}$ The existence of functional thalamocortical connections after 24 W PC was also predicted on the basis of neuroanatomical evidence ${ }^{40,14,19}$ and clinical studies. ${ }^{48,49,26}$ In addition, after 24 . W PC synapses rapidly accumulate in the cortical plate in parallel with the ingrowth of thalamocortical axons $s^{9,21}$ which suggests the development of direct thalamocortical synapses. There is a concurrent devel opment of descending cortical motor pathways to the spinal cord and the brain stem, and corticospinal axons finally enter their target areas in the spinal cord. ${ }^{43}$

In rhesus monkeys of a comparative developmental age, the use of tract-tracing methods enabled a direct demonstration of cortico-striatal connections, ${ }^{44}$ which are also very important for motor behavior. The existence of such cortico-striatal connections in human fetuses was demonstrated indirectly, by cytoarchitectonic changes which reflect an ingrowth and modular arrangement of corticostriatal terminals in the putamen. ${ }^{50}$

W hereas there is no evidence for the establishment of long corticocortical connections between motor cortical regions, the interhemispheric communication may already be mediated by existing callosal fibres. However, studies of event-related potentials suggest that preterm infants al ready display a certain level of cortico-cortical processing of information (for review, see 2).

After 28. WPC, there is an intensive synaptogenesis in developing sublayers of the cortical plate, concurrent with the development of long cortico-cortical pathways and interhemispheric connections. Furthermore, the el aboration of corticomotoneuronal pathway becomes a structural basis for efferent (motor) functions. ${ }^{43,51}$

This transient but distributed cortical network provides a required biological basis for all transient behavioural ${ }^{1}$ and physiological phenomena ${ }^{24}$ observed in preterm infants.

The cortical network in the brain of full-term newborns is still clearly immature. For example, although callosal axons are at the peak of their overproduction phase, they nevertheless did not enter the cortical plate. ${ }^{52,53}$ In addition, there are numerous other signs of immaturity: the circuitry of the deep and transient subplate zone is still prominent; developing cortical layers II-VI of the cortical plate are still immature; the future cortical layer I still contains a number of well-developed fetal Cajal-R etzius cells; layer III pyramidal neurons have very few dendritic spines; granular layer IV ${ }^{54}$ is still present in all parts of the cortex; ${ }^{19}$ and short corticocortical fibers did not reach their final position and continue with active growth. ${ }^{55,56}$

The disappearance of transient fetal elements and growth of short cortico-cortical pathways $5^{55}$ seems to coincide with maturation of general movements. ${ }^{57} \mathrm{~B}$ etween 6 . and 9. postnatal month, transient pathways disappear and there is a rapid devel opment of goal-directed movements (for a review, see in $2,58)$.

Due to the involvement of all cortical areas, i.e. unimodal, heteromodal and transmodal regions of primary, secondary and associative cortex, 9-month-old infants are able to perform delayed-response task ${ }^{59}$ which requires the online presence of executive functions of the frontal lobe together with crucial delayed goal-directed movement in visual absence of the presented object target. It is interesting to note that this frontal cortex function develops simultaneously with the disappearance of transient fetal components, after the reduction in number of exuberant callosal axons ${ }^{53}$ and during the intense overproduction of synapses ${ }^{2,60-62}$ as well as with region-specific metabolic imaging pattern. ${ }^{63}$

\section{THE ROLE OF NEUROIMAGING}

M odern neuroimaging techniques are very important for elucidation of structure-function relationships in normal and abnormal development of the human brain. Although experimental models are important for explanation of basic electrophysiological phenomena, ${ }^{64,5,12,65}$ the proper timing of devel opmental events can be studied in humans only. Four-D ultrasonography ${ }^{3}$ offers an objective perspective on continuity of behavior from prenatal to postnatal life. M agnetic resonance imaging invivo and in utero ${ }^{16,17,18,66-71}$ reveals in great detail a transient laminar organization of the cerebral cortex which underlies transient functional organization. If these fine structural data are correlated with postmortem identification of neural pathways, synaptic distribution and maturation of neurons ${ }^{15}$ one can arrive at the new interpretation of structuralfunctional devel opment in human fetus and preterm infant. For studying neuronal connections, one of the most interesting findings was the visualization of the subplate $z o n e 1^{5,16,28,71}$ which is the thickest and synapse-rich transient compartment of the developing cerebral cortex. ${ }^{14}$ The disappearance of the subplate zone is an excellent indicator of maturity of cortical connections. ${ }^{15}$ On the other hand, lesions of the subplate zone which are frequently seen in preterm infants ${ }^{27-29,72}$ play an essential role in studying cognitive outcome after perinatal hypoxic-ischemic lesions. M odern tractography ${ }^{17,70,71,73}$ offers a unique opportunity to study significance of individual cortical connections and their structural reorganization. ${ }^{74}$

\section{CONCLUSIONS}

Current evidence on devel oping neuronal circuitry in the human cerebrum reveals that development of functional connections between neurons begins early in fetal life and proceeds as a sequence of (partly overlapping) reorganizational events and 
transformations of transient patterns of laminar and cellular organization. The early fetal circuitry is endogeneous and characterized by spontaneous, predominantly oscillatory activity which occurs among early maturing neuronal el ements situated outside the cortical plate. The midfetal period is characterized by the following processes: the pathfinding of afferent axons; their accumulation in the transient subplate zone; the predominance of the deep synaptogenesis with GABA ergic, peptidergic, glutamatergic, cholinergic and monoaminergic transmission. This circuitry, together with efferent projections to striatum and subcortical centers, may form the framework for some fragmented behavioural phenomena.

A fter 24 weeks post conception, thalamocortical fibers relocate to the cortical plate and form synapses conveying peripheral sensory information to cerebral cortex. For a fetal physiology, the initial establishment of thalamocortical connection represents a turning point because from 24 W PC onwards sensory signals (including pain signals) can reach cortical level with prospective sensory-driven activity. During this period, the transient subplate zone is still the most prominent compartment of the developing cerebral cortex. The prolonged coexistence of transient and permanent circuitry is a salient feature of cerebral cortex in preterm infants. This transient pattern of cortical organization, characterized by a progressive deep-to-superficial synaptogenesis in the developing cortex, represents a biological substrate for transient electrophysiological phenomena such as discontinuous oscillations, atypical surface-negative cortical response, and first eventrelated potentials. The neuronal activity in the subplate zone is vital for proper establishment of functional cortical architecture. In the neonatal period, sensory-driven activity is shaping development of cortical columns and plasticity occurs at synaptic level on dendritic spines. ${ }^{31}$

Due to the slow maturation of short corticocortical pathways and interhemispheric synchronization, there is a relatively late postnatal onset (around 8-9 months) of executive and cognitive functions of the frontal lobe. The functional circuitry subserving executive functions of the frontal lobe may be tested by delayedresponse task. ${ }^{59}$

Future research of cortical connections which underlie fetal behavior should be directed towards correlated studies using magnetic resonance DTI and tractography studies, 4Dultrasonography, direct electroencephalographic (EEG) recording, metabolic studies and postmortem studies with immunocytochemical identification of individual neuronal pathways.

\section{ACKNOWLEDGEMENTS}

This work was supported by Croatian Ministry of Science, Education and Sport grants no. 0108118 (to IK) and 0108115 (to MJ).
This paper was published in the book J.M. Carrera, A. K urjak: Conducta F etal: studio ecografico de la neurologia fetal, $B$ arcel ona: M asson 2008. The publisher kindly gave permission to print the paper in Donald School J ournal of UItrasound in Obstetrics and Gynecology.

\section{REFERENCES}

1. DeV ries JIP, V isser GHA, Prechtl HFR. The emergence of fetal behaviour. I. Qualitative aspects. Early Hum Dev 1982;7: 301-22.

2. Kostovic I, J udas M, Petanjek Z, Simic G. Ontogenesis of goaldirected behavior: anatomo-functional considerations. Int J Psychophysiol 1995;19:85-102.

3. Kurjak A, Pooh RK, M erce LT, Carrera JM, Salihagic-K adic A, Andonotopo W. Structural and functional early human development assessed by three-dimensional and fourdimensional sonography. Fertility and Sterility 2005;84(5): 1285-99.

4. Kurjak A, Stanojevic M, A ndonotopo W, Salihagic-Kadic A, Carrera JM, Azumendi G. Behavioral pattern continuity from prenatal to postnatal life- a study by four-dimensional (4D) ultrasonography. J Perinat M ed 2004;32(4):346-53.

5. Friauf E, M cC onnell SK, Shatz CJ. Functional synaptic circuits in the subplate during fetal and early postnatal development of cat visual cortex. J Neurosci 1990;10:2601-13.

6. Friauf $E$, Shatz $\mathrm{CJ}$. Changing patterns of synaptic input to subplate and cortical plate during devel opment of visual cortex. J Neurophysiol 1991;66:2059-71.

7. Penn AA, Shatz CJ. B rain waves and brain wiring: the role of endogenous and sensory-driven neural activity in development. Pediatr Res 1999;45:447-58.

8. Dupont E, Hanganu IL, Kilb W, Hirsch S, Luhmann HJ. Rapid developmental switch in the mechanisms driving early cortical columnar networks. Nature 2006;439:79-83.

9. Molliver ME, Kostovic I, $\mathrm{V}$ an der L oos H. The development of synapses in cerebral cortex of the human fetus. Brain Res 1973;50:403-07.

10. Bystron I, Rakic $P, M$ olnár $Z$, B lakemore $C$. The first neurons of the human cerebral cortex. $N$ at Neurosci 2006;9(7):880-86.

11. Albrieux M, Platel JC, Dupuis A, Villaz M, Moody WJ. J Neurosci 2004;24:1719-25.

12. Hanganu IL, Kilb W, Luhmann HJ. Functional synaptic projections onto subplate neurons in neonatal rat somatosensory cortex. J N eurosci 2002;22:7165-76.

13. Feller M B. Spontaneous correlated activity in developing neural circuits. Neuron 1999;22:653-56.

14. Kostovic I, Rakic P. Developmental history of the transient subplate zone in the visual and somatosensory cortex of the macaque monkey and human brain. J Comp Neurol 1990;297:441-70.

15. Kostovic I, J udas M, Rados M , H rabac P. L aminar organization of the human fetal cerebrum revealed by histochemical markers and magnetic resonance imaging. Cereb Cortex 2002;12:536-44.

16. M aas $L C, M$ ukherjee $P, C$ arballido-Gamio J, et al. Early laminar organization of the human cerebrum demonstrated with diffusion 
tensor imaging in extremely premature infants. Neuroimage 2004;22:1134-40.

17. Judas M, Rados M, Jovanov-M ilosevic N, Hraba P, SternPadovan R, Kostovic I. Structural, immunocytochemical, and $M R$ imaging properties of periventricular crossroads of growing cortical pathways in preterm infants. Am J Neuroradiol 2005;26:2671-84.

18. K ostovic I, J udas M , Skrablin-K ucic S, Stern-Padovan R, Rados $M$. In vivo M R imaging of transient subplate zone in the human fetal telencephalon. Society for N euroscience M eeting (A tlanta) 2006; A bstracts No. 96.10.

19. Kostovic I, Judas M. Correlation between the sequential ingrow th of afferents and transient patterns of cortical lamination in preterm infants. A nat Rec 2002;267:1-6.

20. Fitzgerald $M$. The devel opment of nociceptive circuits. $\mathrm{N}$ at R ev Neurosci 2005;6(7):507-20.

21. Kostovic I, J ovanov-M ilosevic N. The development of cerebral connections during the first 20-46 weeks' gestation. Seminars in Fetal and N eonatal M edicine 2006;xx:1-8.

22. Allendoerfer $K L$, Shat $C$ J . The subplate, a transient neocortical structure: its role in the development of connections between thalamus and cortex. A nnu Rev Neurosci 1994;17:185-218.

23. Kostovic I, Judas M. Prolonged coexistence of transient and permanent circuitry elements in the developing cerebral cortex of fetuses and preterm infants. Dev Med Child Neurol 2006;48:388-93.

24. Dreyfus-Brisac C. Ontogenesis of brain bioelectrical activity and sleep organization in neonates and infants. In Falkner $F$, Tanner JM (Eds): Human Growth V ol. 3: Neurobiology and Nutrition. London: B ailliere Tindall, pp. 1979;157-82.

25. Vanhatalo S, Palva J M, A nderson S, Rivera C, V oipio J, K aila $K$. Slow endogenous activity transients and developmental expression of $\mathrm{K}+\mathrm{Cl}$ - cotransporter 2 in the immature human cortex. Eur J Neurosci 2005;22:2799-27804.

26. V anhatalo S, Kaila K. Develoment of neonatal EEG: from phenomenology to physiology. Semin Fetal Neonatal Med 2006;11:6.

27. Volpe JJ. Encephalopathy of prematurity includes neuronal abnormalities. Pediatrics 2005;116:221-25.

28. M cQuillen PS, Ferriero DM . Perinatal subplate neuron injury: implications for cortical develoment and plasticity. B rain Pathol 2005; 15:250-60.

29. Counsell SJ, Allsop JM; Harrison M C, Larkman DJ, Kennea $\mathrm{NL}$, Kapellou O, Cowan FM, Hajnal JV, Edwards AD, Rutherford MA. Diffusion-weighted imaging of the brain in preterm infants with focal and diffuse white matter abnormality. Pediatrics 2003;112:1-7.

30. B ourgeois JP, J astreboff PJ, Rakic P. Synaptogenesis in visual cortex of normal and preterm monkeys: evidence for intrinsic regulation of synaptic overproduction. Proc $\mathrm{N}$ atl A cad Sci USA 1989;86:4297-301.

31. Katz LC, Crowley JC. Devel opment of cortical circuits: Lessons from ocular dominance columns. Nat Rev Neurosci 2002;3: 34-42.

32. K anold PO, Kara P, R eid RC, Shatz CJ. R ole of subplate neurons in functional maturation of visual cortical columns. Science 2003;301:521-25.
33. K anold PO, Shatz CJ. Subplate neurons regulate maturation of cortical inhibition and outcome of coular dominance plasticity. Neuron 2006;51:627-38.

34. Rakic $P, A$ ng SBC; B reunig J. Setting the stage for cognition: genesis of the primate cerebral cortex. In Gazzaniga M S (Ed): The Cognitive Neurosciences III. New Y ork: MIT Press, 2004;pp.33-49.

35. Nobin A, Björklund A. Topography of the monoamine neuron systems in the human brain as reveal ed in fetuses. A cta Physiol Scand 1973;388/suppl):1-40.

36. Zecevic N, Verney C. Development of the catecholamine neurons in human embryos and fetuses, with special emphasis on the innervation of the cerebral cortex. J Comp Neurol 1995;351:509-35.

37. Kostovic I. Prenatal development of nucleus basalis complex and related fiber systems in man: a histochemical study. Neuroscience 1986;17(4):1047-77.

38. M arin-Padilla M. Prenatal and early postnatal ontogenesis of the human motor cortex: a Golgi study. II. The basket-pyramidal system. Brain Res 1970;23(2):185-91.

39. M rzljak L, Uylings HBM , K ostovic I, V an Eden CG. Prenatal development of neurons in the human prefrontal cortex: I. A qualitative Golgi study. J Comp Neurol 1988;271:355-86.

40. Kostovic I, G oldman-R akic PS. Transient cholinesterase staining in the mediodorsal nucleus of the thalamus and its connections in the developing human and monkey brain. J Comp Neurol 1983;219:431-47.

41. Krmpotic-Nemanic J, Kostovic I, Kelovic Z, Nemanic D, M rzljak L. Development of the human fetal auditory cortex: growth of afferent fibers. A cta A nat 1983;116:69-73.

42. Kostovic I, Rakic P. Development of prestriate visual projections in the monkey and human fetal cerebrum revealed by transient cholinesterase staining. J Neurosci 1984;4:25-42.

43. Eyre JA, M iller S, Clowry GJ, Conway EA, W atts C. Functional corticospinal projections are established prenatally in the human foetus permitting involvement in the development of spinal motor centres. B rain 2000;123(1):51-64.

44. Goldman-Rakic PS. Prenatal formation of cortical input and development of cytoarchitectonic compartments in the neostriatum of the rhesus monkey. J Neurosci 1981;1(7):721-35.

45. Hrbek A, Karlberg P, Olsson T. Development of visual and somatosensory evoked responses in preterm newborn infants. Electroencephalogr Clin Neurophysiol 1973;34:225-32.

46. Graziani LJ, Katz L, Cracco RQ, Cracco JB, Weitzman ED. The maturation and interrelationship of $E E G$ patterns and auditory evoked responses in premature infants. Electroencephalogr Clin Neurophysiol 1974;36:367-75.

47. Novak GP, K urtzberg D, K reuzer J A, V aughan J r HG . Cortical responses to speech sounds and their formants in normal infants: maturational sequence and spatiotemporal analysis. Electroencephalogr Clin N europhysiol 1989;73:295-305.

48. A nand KJ, Hickey PR. Pain and its effects in the human neonate and fetus. N Engl J M ed 1987;317(21):1321-29.

49. Lee SJ, Ralston HJ, Drey EA, Partridge J C, Rosen M A. Fetal pain: a systematic multidisciplinary review of the evidence. JAM A 2005;294(8):947-54. 
50. Kostovic I. D evelopment of cytoarchitectonic compartments in the putamen of the human fetal brain. Verh A nat Ges 1984;78:301-02.

51. EyreJA. D evelopment and plasticity of the corticospinal system in man. N eural Plast 2003;10:93-106.

52. LaM antia A S, Rakic P. A xon overproduction and elimination in the corpus callosum of the developing rhesus monkey. J Neurosci 1990;10(7):2156-75.

53. Innocenti GM, Price DJ. Exuberance in the development of cortical networks. N at Rev N eurosci 2005;6:955-65.

54. Brodmann K. Vergleichende Lokalisationslehre der Grosshirnrinde in ihren Prinzipien dargestellt auf Grund des Zellenbaues. L eipzig: J ohann A mbrosius B arth, 1909.

55. B urkhal ter A. D evel opment of forward and feedback connections between areas V 1 and $V 2$ of human visual cortex. Cereb Cortex 1993;3(5):476-87.

56. Hevner RF. Development of connections in the human visual system during fetal mid-gestation: a Dil-tracing study. J Neuropathol Exp Neurol 2005;59(5):385-92.

57. De Graaf-Peters V B , H adders-A Igra M. Ontogeny of the human central nervous system: what is happening when? E arly H uman Development. 2006;82(4):257-66.

58. Webb SJ, Monk CS, Nelson CA. M echanisms of postnatal neurobiological development: Implications for human development. Dev Neuropsychol 2001;19(2):147-71.

von M onakow C. Gehirnpathologie. Wien: Alfred Hölder (in German), 1905.

59. Diamond A, Doar B. The performance of human infants on a measure of frontal cortex function, the delayed response task. Dev Psychobiol 1989;22:271-94.

60. Zecevic N, B ourgeois JP, Rakic P. Changes in synaptic density in motor cortex of rhesus monkey during foetal and postnatal life. Dev Brain Res 1989;50:11-32.

61. B ourgeois JP, Rakic P. Changes in synaptic density in motor cortex of rhesus-monkey during foetal and postnatal life. Dev Brain Res 1993;50:11-32.

62. Hüttenlocher PR, Dabholkar AS. Regional differences in synaptogenesis in human cerebral cortex. J Comp Neurol 1997;387(2):167-78.
63. Chugani HT, Phelps ME, Mazziotta JC. Positron emission tomography study of human brain functional development. A nn Neurol 1987;22(4):487-97.

64. Molliver ME. A n ontogenetic study of evoked somesthetic cortical responses in the sheep. Prog Brain Res 1967;26:78-91.

65. K hazipov and Luhmann. Early patterns of electrical activity in the developing cerebral cortex of humans and rodents. Trends Neurosci 2006;29(7):414-18.

66. Girard N J, Raybaud CA, Poncet M. In vivo M R study of brain maturation in normal fetuses. A m J Neuroradiol 1995;16: 407-13.

67. Childs A M , R amenghi LA, Evans DJ . M R features of developing periventricular white matter in preterm infants: evidence of glial cell migration. A m J Neuroradiol 1998;19:971-76.

68. Hüppi PS, M urphy $B, M$ aier SE, et al. M icrostructural brain development after perinatal cerebral white matter injury assessed by diffusion tensor magnetic resonance imaging. Pediatrics 2001;107:455-60.

69. $M$ CK instry RC, M athur A, M iller J H, et al. Radial organization of developing preterm human cerebral cortex revealed by noninvasive water diffusion anisotropy MRI. Cereb Cortex 2001;12(12):1237-43.

70. M ukherjee $P, M c K$ instry RC. Diffusion tensor imaging and tractography of human brain development. N euroimag Clin N A m 2006;16:19-43.

71. Glenn $O A, B$ arkovich $A J$. M agnetic resonance imaging of the fetal brain and spine: A $n$ increasingly important tool in prenatal diagnosis, Part 1. A m J Neuroradiol 2006;27:1604-11.

72. Counsell SJ , B oardman JP. D ifferential brain growth in the infant born preterm: current knowledge and future devel opments from brain imaging. Semin Fetal N eonatal M ed 2005;10:403-10.

73. Huang $H$, Zhang J, W akana S, Zhang W, Ren T, Richards LJ, Y arowsky P, Donohue P, Graham E, van Zijl PCM, M ori S. White and gray matter development in human fetal, newborn and pediatric brains. N euro Image 2006;33:27-38.

74. Staudt M, G rodd W, Gerl off C, Erb M, Stitz J , K rägeloh-M ann I. Two types of ipsilateral reorganization in congenital hemiparesis. A TMS and fM RI study. B rain 2002;125:2222-37. 